\title{
Internet gaming disorder in adolescence: Psychological characteristics of a clinical sample
}

\author{
ALEXANDRA TORRES-RODRÍGUEZ ${ }^{1 *}$, MARK D. GRIFFITHS ${ }^{2}$, XAVIER CARBONELL $^{1}$ and URSULA OBERST ${ }^{1}$ \\ ${ }^{1}$ Department of Psychology, FPCEE Blanquerna, Universitat Ramon Llull, Barcelona, Spain \\ ${ }^{2}$ International Gaming Research Unit, Psychology Department, Nottingham Trent University, Nottingham, UK
}

(Received: January 28, 2018; revised manuscript received: May 16, 2018; second revised manuscript received: May 20, 2018; accepted: June 19, 2018)

\begin{abstract}
Background and aims: Internet gaming disorder (IGD) has become a topic of increasing research interest since its inclusion in Section 3 of the DSM-5. Given the lack of clinical studies concerning IGD, exploring the characteristics of clinical samples with IGD will help to delineate the gaming disorder construct and inform future treatment studies. Methods: Data collection consisted of clinical interviews comprising 31 male adolescents diagnosed with IGD. Alongside the clinical interviews, the participants were administered a battery of psychometric tests assessing the following: IGD, personality traits, comorbid symptomatology, emotional intelligence (EI), and family environment characteristics. Results: The results showed that the adolescents with IGD and their relatives reported a high number of hours per week and high presence of stressful life events in the majority of the sample. High scores on scales assessing depression, anxiety, and somatic disorders were found. However, the findings indicate the presence of several other comorbid disorders meaning that some of the adolescent sample with IGD had different clinical profiles. Several personality traits were found to be highly associated with IGD including introversion, inhibition, submissiveness, self-devaluation, interpersonal sensibility, obsessive-compulsive tendencies, phobic anxiety, and hostility, as well as paranoid and borderline personality traits. Other negative characteristics found in the present sample included a high level of social problems, low EI, and dysfunctional family relationships. Discussion and conclusions: The findings suggest a more global pattern of key psychological characteristics associated with Internet gaming disorder in adolescence. This may help in understanding the complexity of this proposed disorder and it may also help in designing more specialized interventions for adolescents with IGD. The findings have important implications for clinical practice and interventions.
\end{abstract}

Keywords: Internet gaming disorder, adolescent gaming, video game addiction, gaming addiction, problematic gaming

\section{INTRODUCTION}

Playing video games is a very popular form of entertainment among children and adolescents as well as among young adults. The video game sector estimates a global growth of $8.5 \%$ among the countries with the biggest revenues: China, USA, Japan, South Korea, Germany, United Kingdom, France, Spain, Canada, and Italy (Newzoo Games, 2016). Despite the benefits that video games have (e.g., entertainment and socialization), clinical and empirical studies have consistently demonstrated that the excessive use of video games may lead to negative consequences in various areas of psychological functioning and can result in an addiction among a small minority of gamers (Ferguson, Coulson, \& Barnett, 2011; Kowert, Festl, \& Quandt, 2014; Kuss \& Griffiths, 2012a; Petry et al., 2014; Torres-Rodríguez, Griffiths, \& Carbonell, 2018; Williams, Yee, \& Caplan, 2008; World Health Organization [WHO], 2014). Adolescence is typically viewed as a life stage where vulnerability to addiction is more pronounced, and is not different for video game addiction (Kuss, van Rooij, Shorter, Griffiths, \& van de Mheen, 2013; López-Fernandez, Honrubia-Serrano, Baguley, \& Griffiths, 2014; Wan \& Chiou, 2006). More specifically, because of cognitive, social, hormonal, and neurobiological immaturities, adolescence is a period of increased risk of experiencing psychological disorders including addictive behaviors (Arnett, 1999; Masten \& Garmezy, 1985; Steinhausen \& Metzke, 2001).

Video game addiction in the form of "Internet gaming disorder" (IGD) was included in Section 3 of the fifth edition of the Diagnostic and Statistical Manual of Mental Disorders (DSM-5; American Psychiatric Association [APA], 2013). In addition, the beta draft of the 11th revision of International Classification of Diseases (ICD-11; WHO, 2016) includes "gaming disorder." The ICD-11 defines this

* Corresponding author: Alexandra Torres-Rodríguez; Department of Psychology, FPCEE Blanquerna, Universitat Ramon Llull, 34 Císter Street, Barcelona 08022, Spain; Phone: +34 9325330 00; Fax: +34 9325330 32; E-mail: alexandrart@blanquerna.url.edu

This is an open-access article distributed under the terms of the Creative Commons Attribution-NonCommercial 4.0 International License, which permits unrestricted use, distribution, and reproduction in any medium for non-commercial purposes, provided the original author and source are credited, a link to the CC License is provided, and changes - if any - are indicated. 
disorder as a recurrent gaming behavior pattern that includes both online and offline gaming. Gaming disorder manifests as an impaired control over gaming and an increasing priority over other life interests and daily activities, leading to recurrent gaming despite increasing negative consequences. The inclusion of gaming disorder by established medical and psychiatric bodies has led to much debate as to whether its inclusion is premature (Aarseth et al., 2016; Griffiths, van Rooij, et al., 2016; Király, Griffiths, \& Demetrovics, 2015; Kuss, Griffiths, \& Pontes, 2017).

A recent meta-analysis estimates the prevalence of IGD between $0.7 \%$ and $15.6 \%$ extracted from studies using naturalistic populations (Feng, Ramo, Chan, \& Bourgeois, 2017). Other prevalence estimate rates of IGD have been reported as 3.1\% (Ferguson et al., 2011), 3\% (Rehbein, Psych, Kleimann, Mediasci, \& Mößle, 2010), and 3.7\% (Kuss et al., 2013). The present study comprised Spanish teenagers and the prevalence rate of IGD among Spanish adolescents has been estimated to be between $6.2 \%$ (MuñozMiralles et al., 2016) and 7.7\% (López-Fernandez et al., 2014).

The clinical importance of the IGD has increased over the past few years, and studies in the gaming literature have involved the evaluation of assessment tools (King, Haagsma, Delfabbro, Gradisar, \& Griffiths, 2013; Pontes, Király, Demetrovics, \& Griffiths, 2014; Pontes \& Griffiths, 2014), diagnostic issues (King \& Delfabbro, 2014; Király et al., 2015; Ko et al., 2014; Petry et al., 2014), risks (Kuss et al., 2013; Rehbein et al., 2010; Tejeiro, Gómez-Vallecillo, Pelegrina, Wallace, \& Emberley, 2012; Wood, Gupta, Derevensky, \& Griffiths, 2004), treatment models (Griffiths, Kuss, \& Pontes, 2016; King, Delfabbro, \& Griffiths, 2010; King, Delfabbro, Griffiths, \& Gradisar, 2012; TorresRodríguez et al., 2018; Young, 2009), experimental treatment studies (Du, Jiang, \& Vance, 2010; Han, Kim, Lee, \& Renshaw, 2015; King et al., 2017; Lindenberg, Halasy, \& Schoenmaekers, 2017; Wölfling, Beutel, Dreier, \& Müller, 2014; Yao et al., 2017; Young, 2013), and case studies (Griffiths, 2010; King et al., 2012; Schwartz, 2013; Torres-Rodríguez \& Carbonell, 2015; Torres-Rodríguez, Griffiths, Carbonell, Farriols-Hernando, \& Torres-Jiménez, 2017; Voss et al., 2015).

Despite increasing research, there are few studies that have examined the clinical characteristics of individuals with IGD or among individuals who seek treatment for video game addiction (Martín-Fernández, Matalí, GarcíaSánchez, Pardo, \& Castellano-Tejedor, 2016). Many studies reporting associated psychological problems and risk factors stem from non-clinical samples in schools and online gamer communities (e.g., Feng et al., 2017; Gentile et al., 2011; Shapira, Goldsmith, Keck, Khosla, \& McElroy, 2000). These IGD studies have reported psychological problems including affective instability, low self-esteem, insecure personality, shyness, loneliness, limited leisure activities, family deficits, maladaptive coping styles, lower social competence, and lower school performance (e.g., Gentile et al., 2011; Kim, Namkoong, Ku, \& Kim, 2008; King \& Delfabbro, 2016; Kuss et al., 2013; Lemmens, Valkenburg, \& Peter, 2011; Liebert, Lo, Ph, Wang, \& Fang, 2005; Rehbein et al., 2010; Schneider, King, \& Delfabbro, 2017; Tejeiro et al., 2012). Other disorders associated with symptoms of IGD include anxiety disorders, depression, suicidal ideation, behavioral disorders, social phobia, autism spectrum disorder (ASD), attention-deficit hyperactivity disorder (ADHD), obsessive-compulsive disorder, and personality disorders (e.g., Andreassen et al., 2016; Chan \& Rabinowitz, 2006; Ferguson et al., 2011; Gentile et al., 2011; Han, Lee, Shi, \& Renshaw, 2014; Kelleci \& Inal, 2010; Kim et al., 2006; Ko et al., 2006; Shapira et al., 2000).

Given the lack of clinical studies concerning IGD, exploring the characteristics of clinical samples with IGD is much required, because several authors have highlighted the importance of individual profiles of social and psychological attributes as predictors of game usage pattern and game preferences (e.g., Greenberg, Sherry, Lachlan, Lucas, \& Holmstrom, 2010; Homer, Hayward, Frye, \& Plass, 2012). Furthermore, analyzing the psychological characteristics of adolescent clinical samples will help to delineate the gaming disorder construct and inform future treatment studies. More specifically, delineating the clinical characteristics of IGD participants will help in designing more specialized psychological treatments for IGD. This is because the etiology of IGD can be diverse (TorresRodríguez et al., 2018) with some treatment studies focusing on gaming as the primary problem and others focusing on the related symptoms (Ferguson et al., 2011) such as lower social competence, emotional intelligence (EI), and symptoms of other comorbid disorders. There is both an empirical and clinical need for an in-depth clinical examination of characteristics associated with IGD. Consequently, the primary aim of this study was to examine the psychological characteristics of treatment-seeking adolescents with gaming disorder recruited via public mental health centers.

\section{METHODS}

\section{Participants}

The initial sample comprised 55 adolescents who voluntarily sought treatment at two public mental health centers in the Barcelona metropolitan area. These individuals represent the complete clinical sample of those seeking treatment and self-declared IGD problems at both centers during the 18-month period when the study was carried out. Out of these, 12 were considered as lost (because they did not return to the treatment center after the first visit) and 12 more were excluded for not meeting the inclusion criteria of this study (four did not meet the inclusion criteria 1 and 2 below; one was younger than 12 years; two presented with a severe mental disorder where the primary disorder needed treating as opposed to the IGD, and five declined to participate in the study). The inclusion criteria were (a) endorsing at least five or more of the nine IGD criteria according to DSM-5 (APA, 2013), (b) scoring 71 or more on IGD-20 Test (Pontes et al., 2014) adapted to Spanish population (Fuster, Carbonell, Pontes, \& Griffiths, 2016), (c) being aged 12-18 years, (d) not having a severe mental disorder or intellectual disability, and (e) understanding the Spanish language. Thus, the final sample consisted of 31 male adolescents diagnosed with IGD. 


\section{Procedure}

Data collection comprised clinical interviews and the administration of several diagnostic instruments to each participant (listed below). Baseline assessments were taken from the 31 participants when they first entered treatment. The clinical interviews were conducted by clinical psychologists, who also applied the diagnostic tests.

\section{Materials}

Demographic data were recorded through a demographic questionnaire and the initial clinical interview. The following scales were used:

Internet Gaming Disorder Test (IGD-20 Test; Pontes et al., 2014). To assess IGD symptoms, the Spanish version of the 20-item IGD-20 Test was used (Fuster et al., 2016). It assesses the symptoms of IGD across six subscales (salience, mood modification, tolerance, withdrawal symptoms, relapse, and conflict). All subscales comprise three items, except conflict, which has five. Answers are scored on a Likert scale from 1 (strongly disagree) to 5 (strongly agree). The minimum and maximum scores are 20 and 100 and, following Pontes et al. (2014), participants who scored 71 or more were classified as having IGD. To compare the results among subscales, the sum scores of each subscale were divided by the number of items of the subscale.

Millon Adolescent Clinical Inventory (MACI; Millon, 1994). The MACI is a widely used, validated, and standardized instrument to assess adolescent personality patterns (12 subscales), expressed concerns ( 8 subscales), and clinical syndromes ( 7 subscales), in addition to four validity (modifying) scales. This study used the Spanish version of MACI and comprised of 160 items. Possible answers were either "true" or "false." The standardized base rate (BR) scores were used in this study, and BR scores of 0 and 115 were selected to represent the minimum and maximum possibilities on each scale. This allowed comparisons between scales and different age ranges using the same data classification on four interpretative clinical benchmarks as follows: no significant difficulties (scores below 60), possible presence of traits (scores between 60 and 74), probable presence of psychopathology (scores between 75 and 85), and presence of a specific personality trait or clinical syndrome (scores over 85). This study followed the scoring guidelines described in the Spanish manual (Millon, 2004).

Symptom Checklist-90-R (SCL-90-R; Derogatis, 1996). The Spanish version of the original SCL-90-R was used to assess psychological distress and symptoms of different mental disorders (Derogatis, 2002). The 90-item SCL-90-R is a widely used and well-validated self-report scale using a 5-point Likert scale (ranging from $0=$ no problem to $4=$ very serious) with minimum and maximum global scores of 0 and 360. The SCL-90-R comprises nine symptom scales (somatization, obsessive-compulsive symptoms, interpersonal sensitivity, depression, anxiety, hostility, phobicanxiety, paranoid ideation, and psychoticism), as well as the following three global indexes: The Global Severity Index (GSI) is considered to be the most sensitive single quantitative indicator concerning individual's psychological distress status (on a scale from 0 to 4 ). It is obtained by dividing the total score by the total number of items (90). The Positive Symptom Total (PST) is the sum of all items with a score equal or above 1 and thus conveys the breadth or array of symptoms that the individual is now experiencing. It can be used as an indicator of whether respondent is attempting to misrepresent his or her status. Finally, the Positive Symptom Distress Index (PSDI) assesses the intensity of the symptoms by multiplying GSI with the total number of items (90) and dividing the product by PST. This study followed the scoring guidelines described in the Spanish manual (Derogatis, 2002).

To assess the behavioral and emotional functioning of the patients, two scales from the Achenbach System of Empirically Based Assessment were used. They were the Youth Self-Report for Ages 11-18 Years (YSR/11-18) and the Child Behavior Checklist for Ages 6-18 Years (CBCL/ 6-18; Achenbach \& Rescorla, 2001). The YSR/11-18 is a 112-item self-report scale completed by the adolescents, and the CBCL/6-18 is the version for their parents. The first part of both instruments assesses the psychosocial competencies of adolescents across four subscales ( 7 items) and the second part assesses behavioral and emotional symptoms across eight subscales (113 items; Table 5). For the scoring, Assessment Data Manager v.910 School-Age Module for CBCL/6-18, Teacher's Report Form for Ages 6-18 (TRF/6-18), and YSR/11-18 was used. Both questionnaires have been validated for the Spanish population, obtaining high validity and internal consistency. For example, the internalizing and externalizing problem scales have been reported as both having a Cronbach's $\alpha$ of .80 (Lemos, Fidalgo, Calvo, \& Menéndez, 1992).

Trait Meta-Mood Scale (TMMS-24; Salovey, Mayer, Goldman, Turvey, \& Palfai, 1995). The TMMS-24 is a 24-item instrument and uses a 5-point Likert scale to assess perceived EI. The Spanish version of the TMMS-24 was used (Fernandez-Berrocal, Extremera, \& Ramos, 2004). The TMMS-24 is widely used in adolescents and adults and comprises three subscales: (a) attention to emotion (participants' self-perception of the degree to which they pay attention to their own moods and emotions), (b) clarity (participants' self-perception of the degree to which they understand their own emotions), and (c) repair of emotion (participants' self-perception of the degree to which they are able to modify their own emotions). The Spanish TMMS-24 has psychometric characteristics similar to the original version with an internal consistency (Cronbach's $\alpha$ ) of .90, .90, and .86 for attention, clarity, and repair, respectively. For this study, the benchmarks for males described in the Spanish version are used (Fernandez-Berrocal et al., 2004).

Family Environment Scale (FES; Moos \& Moos, 1994). The 90-item FES assesses social and environmental characteristics of families across 10 subscales with nine items each in the Spanish version (Seisdedos, Victoria de la Cruz, \& Cordero, 1989). The self-report items are answered as being either "true" or "false" and can be answered by adolescents or adults. The minimum and maximum direct scores are 0 to 9 for the 10 subscales with total scores ranging from 0 to 100 with scores $\leq 50$ being the cut-off point for clinical significance. The original version showed adequate validity and high internal consistency (Cronbach's $\alpha$ of .89). 


\section{Data analysis}

All analyses were conducted with SPSS software version 24. Descriptive analyses were calculated using frequencies and percentages for categorical variables and means and standard deviations ( $S D$ s) for continuous variables. In order to analyze if IGD symptoms were associated with other indices of mental health, Spearman's correlations were calculated between IGD scores and MACI subscales, SCL-90 global indices, and TMMS-24 attention and clarity subscales. Additionally, in order to compare adolescents' perceptions with those of their parents, Spearman's correlations between the results of the YSR/11-18 and the CBCL/6-18 questionnaires were calculated.

\section{Ethics}

The study was approved by the ethics committees of the mental health centers that participated in the studies and the research team's university ethics committee. The participants and their legal guardians signed consent forms. In presenting the cases, information that could identify the participants was anonymized. The study procedures were carried out in accordance with the Declaration of Helsinki.

\section{RESULTS}

\section{Sociodemographic data}

The sociodemographic data of all 31 participants are described in Table 1 . The participants were all males aged between 12 and 18 years (mean $=14.97$ years, $S D=1.74$ ). All participants were Spanish and all except two were students. None of the participants reported any serious physical health problem. Only one participant was then receiving antidepressant medication. However, 19.4\% of the sample had a history of previous psychological treatment and a high number of stressful life events. The most

Table 1. Sociodemographic data of the participants

\begin{tabular}{lc}
\hline & $n(\%)$ \\
\hline Family housing situation & \\
Living with parents & $4(12.9 \%)$ \\
Living with parents and siblings & $11(35.5 \%)$ \\
Shared parental custody & $16(51.6 \%)$ \\
Schooling status & \\
Attending school & $29(93.5 \%)$ \\
Not attending school & $2(6.5 \%)$ \\
Life events & \\
Victim of bullying at school & $12(38.7 \%)$ \\
Own or family illness & $7(22.6 \%)$ \\
Mental disorder in family & $7(22.6 \%)$ \\
Divorce of parents & $16(51.6 \%)$ \\
Substance abuse in family & $5(16.1 \%)$ \\
Domestic violence/neglect/physical abuse & $9(29 \%)$ \\
Death of family member & $5(16.1 \%)$ \\
Economic problems & $8(25.8 \%)$ \\
\hline
\end{tabular}

common stressful life events in the sample were the divorce of the parents and having been bullied at school, as reported by $51.6 \%$ and $38.7 \%$ of the sample, respectively. The adolescents reported an average of $47.51 \mathrm{hr}$ of playing video games per week, whereas their relatives reported their children as playing an average of $49.45 \mathrm{hr}$ per week. The most popular games were the "Multiplayer Online Battle Arena" (MOBA) games and the "Massively Multiplayer Online Role-Playing Games" (MMORPGs), played by $64.5 \%$ and $51.6 \%$, respectively.

\section{Internet gaming disorder}

To assess the IGD symptoms, the IGD-20 Test was used. The sum scores of all the participants exceeded the cut-off point of 71 and were considered as disordered gamers (because they met inclusion criteria 1 and 2). The participants scored uniformly on all subscales (Table 2).

\section{Millon Adolescent Clinical Inventory (MACI)}

The base rate (BR) scores of the subscales and total scale are reported in Table 3. All 31 participants obtained raw scores of 0 on the Reliability (W) scale and scores between 203 and 536 on the Disclosure (X) scale. Many of the personality patterns and expressed concern scales showed an average above the cut-off point of 60 in the following scales: introversion, inhibition, identity diffusion, and peer insecurity, indicating the presence of possible pathological at the domain level. Although most participants did not show alterations in the clinical scales, there were some adolescents with pathological traits in almost all subscales. Clear pathological patterns among participants were identified. There was a significant positive correlation between IGD scores and "anxious feelings" scores $(\rho=.367, p<.05)$, and a significant negative correlation between IGD scores and "oppositional" scores $(\rho=-.416, p<.05)$ and "self-demeaning" scores $(\rho=-.371, p<.05)$.

\section{Symptom Checklist-90-R}

Table 4 shows the number of participants with non-clinical, borderline, and clinical ranges in each symptom scale of SCL-90 and the global indices (GSI, PST, and PSDI).

Table 2. Descriptive statistics [means, $S D$ s, minimum and maximum scores of the IGD-20 subscales, and sum score $(N=31)]$

\begin{tabular}{lccr}
\hline & Mean $\pm S D$ & Min & Max \\
\hline Salience & $4.12 \pm 0.56$ & 3 & 5 \\
Mood modification & $4.17 \pm 0.53$ & 3 & 5 \\
Tolerance & $3.89 \pm 0.75$ & 2 & 5 \\
Withdrawal symptoms & $3.47 \pm 0.60$ & 2 & 5 \\
Conflict & $3.71 \pm 0.40$ & 1 & 5 \\
Relapse & $4.13 \pm 0.67$ & 1 & 5 \\
IGD sum score & $78.0 \pm 5.79$ & 71 & 90 \\
\hline
\end{tabular}

Note. $S D$ : standard deviation; IGD: Internet gaming disorder. 
Table 3. Descriptive overview of MACI scores [means, SDs, SEM, and number and percentage of participants in different benchmark ranges $(N=31)]$

\begin{tabular}{|c|c|c|c|c|c|c|}
\hline Scales of MACI & Mean $\pm S D$ & SEM & $0-59^{\mathrm{a}}$ & $60-74^{\mathrm{a}}$ & $75-84^{\mathrm{a}}$ & $85-120^{\mathrm{a}}$ \\
\hline \multicolumn{7}{|l|}{ Personality Patterns Scales } \\
\hline Introversion (1) & $64.58 \pm 20.43$ & 3.66 & $15(48.4 \%)$ & $9(29.0 \%)$ & $2(6.5 \%)$ & $5(16.1 \%)$ \\
\hline Inhibition (2A) & $60.87 \pm 19.95$ & 3.58 & $16(51.6 \%)$ & $6(19.4 \%)$ & $5(16.1 \%)$ & $4(12.9 \%)$ \\
\hline Doleful (2B) & $49.74 \pm 16.25$ & 2.91 & $20(64.5 \%)$ & $11(35.5 \%)$ & $0(0 \%)$ & $0(0 \%)$ \\
\hline Submissiveness (3) & $58.26 \pm 27.38$ & 4.91 & $15(48.4 \%)$ & $8(25.8 \%)$ & $3(9.7 \%)$ & $5(16.1 \%)$ \\
\hline Dramatizing (4) & $39.71 \pm 28.27$ & 5.07 & $25(80.6 \%)$ & $2(6.5 \%)$ & $2(6.5 \%)$ & $2(6.5 \%)$ \\
\hline Egoistic (5) & $43.65 \pm 26.55$ & 4.76 & $23(74.2 \%)$ & $4(12.9 \%)$ & $0(0 \%)$ & $4(12.9 \%)$ \\
\hline Unruly (6A) & $45.97 \pm 20.55$ & 3.69 & $22(71.0 \%)$ & $7(22.5 \%)$ & $1(3.2 \%)$ & $1(3.2 \%)$ \\
\hline Forceful (6B) & $49.58 \pm 21.76$ & 3.90 & $24(77.4 \%)$ & $2(6.5 \%)$ & $1(3.2 \%)$ & $4(12.9 \%)$ \\
\hline Conforming (7) & $54.81 \pm 28.28$ & 5.08 & $18(58.1 \%)$ & $7(22.5 \%)$ & $0(0 \%)$ & $6(19.4 \%)$ \\
\hline Oppositional (8A) & $52.32 \pm 19.42$ & 3.488 & $20(64.5 \%)$ & $8(25.8 \%)$ & $3(9.7 \%)$ & $2(6.5 \%)$ \\
\hline Self-demeaning (8B) & $50.68 \pm 19.64$ & 3.52 & $21(67.7 \%)$ & $6(19.4 \%)$ & $3(9.7 \%)$ & $1(3.2 \%)$ \\
\hline Borderline tendency (9) & $55.77 \pm 17.31$ & 3.11 & $17(54.8 \%)$ & $11(35.5 \%)$ & $1(3.2 \%)$ & $2(6.5 \%)$ \\
\hline \multicolumn{7}{|l|}{ Expressed Concern Scales } \\
\hline Identity diffusion (A) & $63.42 \pm 19.07$ & 3.42 & $11(35.5 \%)$ & $14(45.1 \%)$ & $2(6.5 \%)$ & $4(12.9 \%)$ \\
\hline Self-devaluation (B) & $56.52 \pm 20.65$ & 3.71 & $17(54.8 \%)$ & $9(29.0 \%)$ & $2(6.5 \%)$ & $3(9.7 \%)$ \\
\hline Body disapproval (C) & $52.74 \pm 21.09$ & 3.78 & $20(64.5 \%)$ & $5(16.1 \%)$ & $5(16.1 \%)$ & $1(3.2 \%)$ \\
\hline Sexual discomfort (D) & $29.06 \pm 7.03$ & 1.26 & $23(74.2 \%)$ & $2(6.5 \%)$ & $5(16.1 \%)$ & $1(3.2 \%)$ \\
\hline Peer insecurity (E) & $62.16 \pm 26.67$ & 4.79 & $12(38.7 \%)$ & $9(29.0 \%)$ & $4(12.9 \%)$ & $6(19.4 \%)$ \\
\hline Social insensitivity (F) & $44.61 \pm 25.10$ & 4.50 & $23(74.2 \%)$ & $5(16.1 \%)$ & $1(3.2 \%)$ & $2(6.5 \%)$ \\
\hline Family discord (G) & $55.35 \pm 25.48$ & 4.57 & $16(51.6 \%)$ & $11(35.5 \%)$ & $0(0 \%)$ & $4(12.9 \%)$ \\
\hline Childhood abuse $(\mathrm{H})$ & $52.71 \pm 20.12$ & 3.61 & $19(61.3 \%)$ & $9(29.0 \%)$ & $2(6.5 \%)$ & $1(3.2 \%)$ \\
\hline \multicolumn{7}{|l|}{ Clinical Syndrome Scales } \\
\hline Eating dysfunctions (AA) & $48.42 \pm 22.15$ & 3.97 & $20(64.5 \%)$ & $9(29.0 \%)$ & $0(0 \%)$ & $2(6.5 \%)$ \\
\hline Substance abuse (BB) & $45.87 \pm 18.04$ & 3.24 & $25(80.6 \%)$ & $5(16.1 \%)$ & $1(3.2 \%)$ & $0(0 \%)$ \\
\hline Delinquent predisposition (CC) & $39.26 \pm 19.34$ & 0.99 & $27(87.1 \%)$ & $3(9.7 \%)$ & $1(3.2 \%)$ & $0(0 \%)$ \\
\hline Impulsive propensity (DD) & $46.90 \pm 22.39$ & 4.02 & $23(74.2 \%)$ & $4(12.9 \%)$ & $1(3.2 \%)$ & $3(9.7 \%)$ \\
\hline Anxious feelings (EE) & $58.77 \pm 20.22$ & 3.63 & $17(54.8 \%)$ & $8(25.8 \%)$ & $3(9.7 \%)$ & $3(9.7 \%)$ \\
\hline Depressive affect (FF) & $56.87 \pm 17.82$ & 3.20 & $16(51.6 \%)$ & $13(41.9)$ & $0(0 \%)$ & $2(6.5 \%)$ \\
\hline Suicidal tendency (GG) & $51.48 \pm 14.95$ & 2.68 & $23(74.2 \%)$ & $7(22.6 \%)$ & $0(0 \%)$ & $1(3.2 \%)$ \\
\hline
\end{tabular}

Note. SD: standard deviation; MACI: Millon Adolescent Clinical Inventory; SEM: standard error of measurement.

${ }^{a}$ Scores $0-59=$ no significant difficulties; $60-74=$ possible presence of traits at the domain level; $75-85=$ likely psychopathology is present; $>85=$ presence of personality pattern likely at an impairing level.

Table 4. Descriptive overview of SCL-90 scoresoverview of SCL-90 scores [means, SDs, and number and percentage of participants in different benchmark range $(N=31)]$

\begin{tabular}{|c|c|c|c|c|c|c|}
\hline & \multicolumn{3}{|c|}{ Descriptive data } & \multicolumn{3}{|c|}{ Interpretative benchmarks } \\
\hline & Mean $\pm S D$ & Min & $\operatorname{Max}$ & Non-clinical & Borderline & Clinical \\
\hline Somatization & $0.78 \pm 0.90$ & 0 & 4.0 & $9(29.0 \%)$ & $7(22.6 \%)$ & $15(48.4 \%)$ \\
\hline Obsessive-compulsive & $1.32 \pm 0.67$ & 0.20 & 2.70 & $3(16.1 \%)$ & $5(16.1 \%)$ & $23(74.2 \%)$ \\
\hline Interpersonal sensitivity & $1.29 \pm 0.98$ & 0 & 3.54 & $6(19.4 \%)$ & $2(6.4 \%)$ & $23(74.2 \%)$ \\
\hline Depression & $1.24 \pm 0.94$ & 0.15 & 3.54 & $8(25.8 \%)$ & $3(9.7 \%)$ & $20(64.5 \%)$ \\
\hline Anxiety & $0.82 \pm 0.63$ & 0 & 3.67 & $8(25.8 \%)$ & $4(12.9 \%)$ & $19(61.3 \%)$ \\
\hline Hostility & $1.33 \pm 1.04$ & 0 & 3.67 & $5(16.1 \%)$ & $5(16.1 \%)$ & $21(67.8 \%)$ \\
\hline Phobic anxiety & $0.67 \pm 0.77$ & 0 & 2.86 & $7(22.6 \%)$ & $2(6.5 \%)$ & $22(70.9 \%)$ \\
\hline Paranoid ideation & $1.08 \pm 0.85$ & 0 & 3.83 & $6(19.4 \%)$ & $2(6.5 \%)$ & $23(74.2 \%)$ \\
\hline Psychoticism & $0.67 \pm 0.67$ & 0 & 2.60 & $13(41.9 \%)$ & $8(25.8 \%)$ & $10(32.3 \%)$ \\
\hline Global Severity Index & $1.02 \pm 0.63$ & 0.21 & 2.79 & $2(6.5 \%)$ & $4(12.9 \%)$ & $25(80.6 \%)$ \\
\hline Positive symptom total & $43.7 \pm 18.13$ & 13 & 79.0 & $1(3.2 \%)$ & $3(9.7 \%)$ & $27(87.1 \%)$ \\
\hline Positive Symptom Distress Index & $2.0 \pm 0.62$ & 1 & 3.35 & $7(22.6 \%)$ & $9(29.0 \%)$ & $15(48.4 \%)$ \\
\hline
\end{tabular}

Note. The classification of non-clinical (0-45), borderline (50-65), and clinical (70-99) was done using the male adolescents' non-psychiatric $t$-scores. SCL-90: Symptom Checklist-90-R; SD: standard deviation.

The clinical characteristics at the beginning of treatment (baseline) indicated that most of the participants had comorbid psychological problems and symptoms of psychopathology within the clinical range. There is also some variabilities in the clinical profiles in the sample. The primary symptom dimensions with clinical scores were common among the sample, 
including comorbid symptoms related to obsessivecompulsive, interpersonal sensitivity, depression, anxiety, hostility, phobic anxiety, and paranoid ideation dimensions. Overall, $80.6 \% \quad(n=25)$ of the sample had significantly high psychological distress with a range of different comorbid symptoms. The IGD scores significantly correlated with scores on "interpersonal sensitivity" $(\rho=.442$, $p<.05)$, "hostility" $(\rho=.363, p<.05)$, "GSI" $(\rho=.360$, $p<.05)$, and "PSDI" $(\rho=.473, p<.01)$.

Youth self-report for ages 11-18 years (YSR/11-18) and the child behavior checklist for ages 6-18 years (CBCL/6-18)

The YSR/11-18 and CBCL/6-18 were used to compare the perceptions from the participants (YSR/11-18) with those of their families (CBCL/6-18). Table 5 shows the means, $S D$ s, SEM, as well as the number and percentage of participants falling into the non-clinical, borderline, and clinical categories. Regarding the competence scales, there was a lack of presence of activities and social relationships and a high percentage of participants showing clinically significant scores. Similarly, the total competence scale mean was classified within the clinical range $(23.93 \pm 7.01)$. The clinical scores presented by the participants differed across the syndrome scales. Being "withdrawn/depressed" had the highest clinical mean, followed by the "anxious/depressed" scale. The scores on the symptom scales denoted clinical status in all total scales: internalizing problems $(69.65 \pm 9.29)$, externalizing problems $(61.77 \pm 8.32)$, and total problems $(68.10 \pm$ $6.89)$. The IGD score correlated significantly with the following CBCL/6-18 scales: "anxious/depressed" $(\rho=.356, \quad p<.05), \quad$ "withdrawn/depressed" $\quad(\rho=.371$, $p<.05)$, and "internalizing problems" $(\rho=.407, p<.05)$. Regarding the YSR/11-18, there was a significant negative correlation on the activity competence scale $(\rho=-.572$, $p<.01)$.

Table 5. Descriptive overview of YSR/11-18 and CBCL/6-18 scores [means, SDs, SEM, and number and percentage of participants in different benchmark range $(N=31)]$

\begin{tabular}{|c|c|c|c|c|c|c|c|}
\hline & & Mean $\pm S D$ & SEM & Correlations & Non-clinical & Borderline & Clinical \\
\hline Competence scales & & & & & $65-36$ & $35-31$ & 30-20 \\
\hline \multirow[t]{2}{*}{ Activities } & YSR & $30.0 \pm 6.11$ & 1.09 & \multirow{2}{*}{ n.s. } & $6(19.4 \%)$ & $9(29.0 \%)$ & $16(51.6 \%)$ \\
\hline & CBCL & $27.38 \pm 7.15$ & 1.28 & & $4(12.8 \%)$ & $5(16.2 \%)$ & $22(71.0 \%)$ \\
\hline \multirow[t]{2}{*}{ Social } & YSR & $34.7 \pm 14.65$ & 2.63 & \multirow{2}{*}{$0.699 * * *$} & $6(19.4 \%)$ & $8(25.8 \%)$ & $15(48.4 \%)$ \\
\hline & CBCL & $31.41 \pm 8.10$ & 1.46 & & $8(25.8 \%)$ & $6(19.4 \%)$ & $17(54.8 \%)$ \\
\hline \multirow[t]{3}{*}{ School $^{\mathrm{a}}$} & $\mathrm{YSR}^{\mathrm{b}}$ & - & - & \multirow[b]{2}{*}{-} & - & - & - \\
\hline & CBCL & $37.06 \pm 7.26$ & 1.35 & & $18(59.5 \%)$ & $4(12.9 \%)$ & $7(27.6 \%)$ \\
\hline & & & & \multirow{3}{*}{$0.504 * *$} & $80-41$ & 40-37 & $36-10$ \\
\hline \multirow[t]{2}{*}{ Total competence scales ${ }^{a}$} & YSR & $27.96 \pm 9.16$ & 1.70 & & $0(0 \%)$ & $4(13.8 \%)$ & $25(86.2 \%)$ \\
\hline & CBCL & $23.93 \pm 7.01$ & 1.30 & & $0(0 \%)$ & $2(6.5 \%)$ & $27(93.1 \%)$ \\
\hline Syndrome scales & & & & & $50-65$ & $66-69$ & $70-100$ \\
\hline \multirow[t]{2}{*}{ I - Anxious/depressed } & YSR & $61.26 \pm 8.63$ & 1.55 & \multirow{2}{*}{$0.627 * * *$} & $21(67.7 \%)$ & $3(9.7 \%)$ & $7(22.6 \%)$ \\
\hline & CBCL & $66.1 \pm 10.06$ & 1.80 & & $16(51.6 \%)$ & $3(9.7 \%)$ & $12(38.7 \%)$ \\
\hline \multirow[t]{2}{*}{ II - Withdrawn/depressed } & YSR & $64.65 \pm 9.93$ & 1.78 & \multirow{2}{*}{$0.522 * *$} & $19(61.3 \%)$ & $4(12.9 \%)$ & $8(25.8 \%)$ \\
\hline & CBCL & $78.13 \pm 2.57$ & 2.57 & & $4(12.9 \%)$ & $6(19.4 \%)$ & $21(67.7 \%)$ \\
\hline \multirow{2}{*}{ III - Somatic complaints } & YSR & $58.52 \pm 8.74$ & 1.57 & \multirow{2}{*}{$0.521 * *$} & $24(77.4 \%)$ & $3(9.7 \%)$ & $4(12.9 \%)$ \\
\hline & CBCL & $63.52 \pm 9.89$ & 1.77 & & $19(61.3 \%)$ & $1(3.2 \%)$ & $11(35.5 \%)$ \\
\hline \multirow[t]{2}{*}{ IV - Social problems } & YSR & $61.45 \pm 8.87$ & 1.59 & \multirow{2}{*}{ n.s. } & $19(61.3 \%)$ & $5(16.2 \%)$ & $7(22.6 \%)$ \\
\hline & CBCL & $64.0 \pm 9.15$ & 1.64 & & $15(48.4 \%)$ & $9(29.0 \%)$ & $7(27.6 \%)$ \\
\hline \multirow[t]{2}{*}{ V - Thought problems } & YSR & $56.26 \pm 5.74$ & 1.03 & \multirow[b]{2}{*}{ n.s. } & $29(93.5 \%)$ & $1(3.2 \%)$ & $1(3.2 \%)$ \\
\hline & CBCL & $64.95 \pm 7.35$ & 1.32 & & $16(51.6 \%)$ & $5(16.2 \%)$ & $10(67.8 \%)$ \\
\hline \multirow[t]{2}{*}{ VI - attention problems } & YSR & $65.1 \pm 10.12$ & 1.80 & \multirow{2}{*}{ n.s. } & $17(54.8 \%)$ & $6(19.4 \%)$ & $8(25.8 \%)$ \\
\hline & CBCL & $65.87 \pm 8.37$ & 1.50 & & $20(64.5 \%)$ & $5(16.2 \%)$ & $6(19.4 \%)$ \\
\hline \multirow[t]{2}{*}{ VII - rule-breaking behavior } & YSR & $56.55 \pm 5.75$ & 1.03 & \multirow{2}{*}{$0.692 * * *$} & $27(87.1 \%)$ & $3(9.7 \%)$ & $0(0 \%)$ \\
\hline & CBCL & $59.55 \pm 5.40$ & 0.97 & & $27(87.1 \%)$ & $4(12.9 \%)$ & $0(0 \%)$ \\
\hline \multirow[t]{2}{*}{ VIII - aggressive behavior } & YSR & $60.32 \pm 10.42$ & 1.87 & \multirow{2}{*}{$0.665^{* * *}$} & $24(77.4 \%)$ & $2(6.5 \%)$ & $5(16.2 \%)$ \\
\hline & CBCL & $64.03 \pm 9.21$ & 1.65 & & $18(58.1 \%)$ & $3(9.7 \%)$ & $10(67.8 \%)$ \\
\hline \multicolumn{5}{|l|}{ Total scales } & $50-59$ & $60-63$ & 64-100 \\
\hline \multirow[t]{2}{*}{ Internalizing problems } & YSR & $61.94 \pm 9.88$ & 1.77 & \multirow{2}{*}{$0.607^{* * *}$} & $11(35.5 \%)$ & $4(12.9 \%)$ & $16(51.6 \%)$ \\
\hline & CBCL & $69.65 \pm 9.29$ & 1.67 & & $5(16.2 \%)$ & $1(3.2 \%)$ & $25(80.6 \%)$ \\
\hline \multirow[t]{2}{*}{ Externalizing problems } & YSR & $57.77 \pm 8.27$ & 1.48 & & $20(64.5 \%)$ & $5(16.2 \%)$ & $6(19.4 \%)$ \\
\hline & CBCL & $61.77 \pm 8.32$ & 1.49 & $0.627 * * *$ & $9(29.0 \%)$ & $8(25.8 \%)$ & $14(45.2 \%)$ \\
\hline Total problems & YSR & $62.16 \pm 6.28$ & 1.12 & & $11(35.5 \%)$ & $9(29.0 \%)$ & $11(35.5 \%)$ \\
\hline & CBCL & $68.10 \pm 6.89$ & 1.23 & $0.430^{*}$ & $3(9.7 \%)$ & $3(9.7 \%)$ & $25(80.6 \%)$ \\
\hline
\end{tabular}

Note. The bold values pretends to classify the scores in ranges "non-clinical," "borderline," and "clinical" scores. SD: standard deviation; YSR: Youth Self-Report; CBCL: Child Behavior Checklist; SEM: standard error of measurement.

${ }^{\mathrm{a}}$ Missing score of two individuals who are not attending to school $(n=2,6.5 \%)$. ${ }^{\mathrm{b}}$ System missing.

${ }^{*} p<.05 .{ }^{* *} p<.01 .{ }^{* * *} p>.001$. 
Table 6. Descriptive statistics of the TMMS-24 [means, SDs, SEM, and number and percentage of participants laying in the different classification ranges $(N=31)]$

\begin{tabular}{|c|c|c|c|c|c|}
\hline & \multirow[b]{2}{*}{ Mean $\pm S D$} & \multirow[b]{2}{*}{ SEM } & \multicolumn{3}{|c|}{$n(\%)$} \\
\hline & & & Low $(\leq 21)$ & Adequate $(22-32)$ & Excessive $(\geq 33)^{\mathrm{a}}$ \\
\hline Attention to feelings & $18.48 \pm 7.14$ & 1.28 & $21(67.7 \%)$ & $8(25.8 \%)$ & $2(6.5 \%)$ \\
\hline & & & Low $(\leq 25)$ & Adequate (26-35) & Excellent $(\geq 36)$ \\
\hline Clarity of feelings & $21.74 \pm 6.0$ & 1.07 & $25(80.6 \%)$ & $5(16.1 \%)$ & $1(3.2 \%)$ \\
\hline Mood repair & $21.48 \pm 5.03$ & 0.90 & $19(61.3 \%)$ & $12(38.7 \%)$ & $0(0 \%)$ \\
\hline
\end{tabular}

Note. SD: standard deviation; TMMS-24: Trait Meta-Mood Scale; SEM: standard error of measurement.

${ }^{a}$ Only in the attention dimension, scores equal or above 33 are considered as excessive, not excellent as in the other two dimensions.

\section{Emotional intelligence}

Table 6 presents the information related to EI assessed with the TMMS-24. A high percentage of participants presented scores in the lower range thus showing deficits in EI. The overall means also were lower than scores classified in adequate range. However, there was no significant correlation between the IGD-20 scores and the scores of the TMMS-24 dimensions.

\section{Family Environment Scale (FES)}

The results regarding the Family Environment scale are presented in Table 7. Cohesion and expressivity scores were low reflecting poor family cohesion in 24 participants $(77.4 \%)$ and poor familiar expressivity in 20 participants $(64.5 \%)$. The conflict scale score must be interpreted considering that scores $\leq 50$ mean conflict presence. In this sample, 11 individuals (35.5\%) and 9 individuals (29\%) showed a moderate and remarkable conflict presence in the family, respectively. Regarding the subscales of personal growth indices, independence, achievement orientation, intellectual-cultural orientation, and moral-religious emphasis all showed low scores meaning a poor presence of these attributes in the participants' families. The organization and control scales showed a tendency for low organization in 17 families and a tendency of high control in 20 families $(\leq 5)$. The results in Table 7 show a tendency of negative family relationship, absence of family growth characteristics, and control-disorganized families. Consequently and considering the scores outlined above, a negative family relationship and environment was common in the present sample.

\section{DISCUSSION}

This is the first study to examine the psychological characteristics of a clinical sample of adolescents with Internet gaming disorder recruited through two public mental-health centers. The weekly gameplay $(47.51 \mathrm{hr})$ appears to be high in this sample compared to the findings of other studies where $30 \mathrm{hr}$ per week was reported among disordered players (e.g., Fuster et al., 2016; Pontes et al., 2014). In addition, it appears that younger gamers play more hours than older gamers (Fuster et al., 2016). The adolescents in this study preferred MMOPRG and MOBA games. This is in accordance with other studies where those who played MMORPGs and MOBA games reported poor well-being and mental health and reported more hours played than other gamer groups (Fuster et al., 2016; Smyth, 2007).

The findings of this study demonstrated that the participants obtained uniform scores among IGD-20 subscales (i.e., salience, mood modification, tolerance, withdrawal, relapse, and conflict symptoms). In the disorder gamer profile founded by Pontes et al. (2014), symptoms, such

Table 7. Family environment characteristics through FES scores (means, SDs, SEM, and number and percentage of participants in different benchmark ranges)

\begin{tabular}{lccccc}
\hline & Mean $\pm S D$ & SEM & Low presence (1-4) & Average presence (5-6) & High presence (7-9) \\
\hline Family Relationship Index & & & & & \\
$\quad$ Cohesion & $3.03 \pm 2.49$ & 0.44 & $24(77.4 \%)$ & $4(12.9 \%)$ & $3(9.7 \%)$ \\
$\quad \begin{array}{l}\text { Expressivity } \\
\text { Conflict }\end{array}$ & $4.06 \pm 2.04$ & 0.36 & $20(64.5 \%)$ & $7(22.6 \%)$ & $4(12.9 \%)$ \\
$\begin{array}{l}\text { Personal Growth Index } \\
\text { Independence }\end{array}$ & $5.13 \pm 1.80$ & 0.32 & $11(35.5 \%)$ & $11(35.5 \%)$ & $9(29.0 \%)$ \\
Achievement & $4.48 \pm 1.87$ & 0.33 & $13(41.9 \%)$ & $14(45.2 \%)$ & $4(12.9 \%)$ \\
Intellectual-cultural & $2.81 \pm 1.85$ & 0.33 & $17(54.8 \%)$ & $7(22.6 \%)$ & $7(22.6 \%)$ \\
Active-recreational & $2.84 \pm 1.26$ & 0.28 & $26(83.9 \%)$ & $5(16.1 \%)$ & $0(0 \%)$ \\
$\quad$ Moral-religious & $2.32 \pm 1.37$ & 0.22 & $29(93.5 \%)$ & $2(6.5 \%)$ & $0(0 \%)$ \\
System Maintenance Index & & $29(93.5 \%)$ & $2(6.5 \%)$ & $0(0 \%)$ \\
$\quad$ Organization & $4.68 \pm 2.05$ & 0.36 & $17(54.8 \%)$ & $6(19.4 \%)$ & $3(9.7 \%)$ \\
Control & $5.55 \pm 1.84$ & 0.33 & $13(41.9 \%)$ & $11(35.5 \%)$ & $9(29.1 \%)$ \\
\hline
\end{tabular}

Note. SD: standard deviation; SEM: standard error of measurement; FES: Family Environment Scale. 
as conflict, were critical in determining the pathological use of online video game playing (King, Delfabbro, Zwaans, \& Kaptsis, 2013).

Multiple negative environmental factors were found among disordered gamers in this study. The majority of the sample had undergone stressful life events in concordance with other studies in the field (Leung, 2007; Yan, Li, $\&$ Sui, 2014). Other negative characteristics found in the present sample included a high level of social problems and negative family patterns, such as conflicted functioning and poor family relationships, and findings that are also in accordance with previous research (e.g., Yan et al., 2014). Moreover, Bonnaire and Phan (2017) found a strong influence of family conflict and a poorer family relationship on the occurrence of IGD in adolescents. In addition, a very high number of adolescents reported school failure, poor social environment, and shortage of engaging in alternative activities to playing video games. These findings confirm other studies showing correlations between IGD in adolescence and risk factors reported in this study (Beutel, Hoch, Wölfling, \& Mueller, 2011; Ferguson et al., 2011)

In relation to other psychological characteristics, several personality traits were found to be highly associated with IGD including introversion, inhibition, submissiveness, self-devaluation, interpersonal sensibility, obsessivecompulsive tendencies, phobic anxiety, and hostility, as well as paranoid and borderline personality traits. Similar findings have been reported in several studies using nonclinical samples (Griffiths, van Rooij, et al., 2016; Zadra et al., 2016), as well as associations between IGD and boredom inclination, sensation-seeking, and schizoid traits. As previous research has demonstrated, it is essential to include EI as an indicator of psychological distress (Beranuy, Oberst, Carbonell, \& Chamarro, 2009) when examining psychological characteristics of those with IGD. Furthermore, having good EI is a good mental health predictor (Martins, Ramalho, \& Morin, 2010), whereas poor EI is likely to act as a predictor of addiction-related behaviors (Engelberg \& Sjöberg, 2004; Parker, Taylor, Eastabrook, Schell, \& Wood, 2008), particularly in the adolescents (Parker, Summerfeldt, Taylor, Kloosterman, \& Keefer, 2013). As previous research has demonstrated, the EI findings in this study showed a tendency toward being clinically significant and can be viewed as a lack of skills in this area of psychological functioning.

In both the global scores and subscale scores of the SCL-90, YSR/11-18, and CBCL/6-18, the sample in this study had high clinical scores indicating multiple clinical symptoms and underlying mental distress. Previous research has demonstrated an association between high levels of distress and online addictions (Mentzoni et al., 2011; Yan et al., 2014). Ng and Wiemer-Hastings (2005) found that gamers with a psychosocial vulnerability were susceptible to pathological involvement with online games. In all the participants, other comorbidities besides IGD were diagnosed by clinicians. This has been reported by other studies highlighting the high rates of comorbid psychiatric disorders (Bozkurt, Coskun, Ayaydin, Adak, \& Zoroglu, 2013; Ferguson et al., 2011; Müller, Beutel, Egloff, \& Wölfling, 2014).
While many of the gamers in the present sample had high scores on scales assessing depression, anxiety, and somatic disorders, the presence of several other comorbid disorders meant there were different clinical profiles of adolescents with IGD in the sample. The relationship between IGD and other problems has been reported in previous studies, concerning IGD and its relationship with depression, anxiety, ADHD, ASD, obsessive-compulsive symptoms, and behavioral disorders (Andreassen et al., 2016; Brunborg, Mentzoni, \& Frøyland, 2014; Carli et al., 2013; Ceyhan \& Ceyhan, 2008; King, Delfabbro, \& King, 2016; Kuss \& Griffiths, 2012b; Müller et al., 2015; van Rooij et al., 2014).

\section{CONCLUSIONS}

As far as the authors are aware, this is the first study to examine the psychological characteristics among a clinical sample of adolescents with IGD. Furthermore, this study analyzed several psychological characteristics as regards the sociodemographic data, IGD symptoms, personality traits, comorbid disorders, EI, and the family functioning. Consequently, the findings presented here have important implications for clinical practice and interventions. By studying all the psychological patterns simultaneously, the findings point toward a more global pattern of key psychological characteristics associated with Internet gaming disorder in the adolescence. This may help in understanding the complexity of this proposed disorder given the many different psychological characteristics and vulnerabilities, and it may also help in designing more complex and global interventions for adolescents with IGD. The findings suggest an integrative approach for specialized treatments including the treatment of comorbid disorders, as well as interventions that address low self-esteem, poor social skills, low EI, and family dysfunction (among others) in order to address the disorder more holistically.

Despite its novelty, this study is not without limitations. These should be kept in mind when interpreting the findings. First, most of the data collected were self-report in nature. However, all scales used were previously validated, psychometrically robust, and had good internal consistency. Furthermore, MACI inventories add validity to scales in dealing with the common problems of self-reported tests such as reliability, disclosure, social desirability, and debasement. Second, the sample size was modest limiting the results obtained. However, for a clinical sample, the sample size was much bigger than other case studies reported in the prior literature. Third, being a clinical sample, the generalization of the findings to other populations is limited although the major criticism of the existing data is that it tends to come from non-clinical samples. Finally, there was no control group to compare the results. However, on the whole, the findings of this study provide a valuable contribution the IGD literature.

Funding sources: This study was supported by personal Blanquerna Research Grant (BRB) to AT-R. 
Authors' contribution: AT-R, MG, and XC contributed to study concept and design and to writing and review of the manuscript. AT-R and UO contributed in analysis and interpretation of data. UO contributed to writing and review of the manuscript. AT-R had access to the sample. All authors had full access to all data in the study and take responsibility for the integrity of the data and the accuracy of the data analysis.

Conflict of interest: The authors report no financial or other relationship relevant to the subject of this article.

Acknowledgements: The authors would like to thank all the participants and their families.

\section{REFERENCES}

Aarseth, E., Bean, A. M., Boonen, H., Colder Carras, M., Coulson, M., Das, D., Deleuze, J., Dunkels, E., Edman, J., Ferguson, C. J., Haagsma, M. C., Helmersson Bergmark, K., Hussain, Z., Jansz, J., Kardefelt-Winther, D., Kutner, L., Markey, P., Nielsen, R. K. L., Prause, N., Przybylski, A., Quandt, T., Schimmenti, A., Starcevic, V., Stutman, G., Van Looy, J., \& Van Rooij, A. J. (2016). Scholars' open debate paper on the World Health Organization ICD-11 gaming disorder proposal. Journal of Behavioral Addictions, 6(3), 1-4. doi:10.1556/2006.5.2016.088

Achenbach, T. M., \& Rescorla, L. A. (2001). Manual for the ASEBA school-age forms \& profiles. Burlington, VT: ASEBA.

American Psychiatric Association [APA]. (2013). DSM-5: Diagnostic and statistical manual of mental disorders (5th ed.). Washington, DC: American Psychiatric Association.

Andreassen, C. S., Billieux, J., Griffiths, M. D., Kuss, D. J., Demetrovics, Z., Mazzoni, E., \& Pallesen, S. (2016). The relationship between addictive use of social media and video games and symptoms of psychiatric disorders: A large-scale cross-sectional study. Psychology of Addictive Behaviors, 30(2), 252-262. doi:10.1037/adb0000160

Arnett, J. J. (1999). Adolescent storm and stress, reconsidered. American Psychologist, 54(5), 317-326. doi:10.1037/0003066X.54.5.317

Beranuy, M., Oberst, U., Carbonell, X., \& Chamarro, A. (2009). Problematic Internet and mobile phone use and clinical symptoms in college students: The role of emotional intelligence. Computers in Human Behavior, 25(5), 1182-1187. doi:10.1016/j.chb.2009.03.001

Beutel, M. E., Hoch, C., Wölfling, K., \& Mueller, K. W. (2011). Characteristics of computer game and Internet addiction in persons seeking treatment in an outpatient clinic for computer game addiction. Zeitschrift Fur Psychosomatische Medizin Und Psychotherapie, 57(1), 77-90. doi:10.13109/zptm.2011. 57.1.77

Bonnaire, C., \& Phan, O. (2017). Relationships between parental attitudes, family functioning and Internet gaming disorder in adolescents attending school. Psychiatry Research, 255, 104-110. doi:10.1016/j.psychres.2017.05.030

Bozkurt, H., Coskun, M., Ayaydin, H., Adak, I., \& Zoroglu, S. S. (2013). Prevalence and patterns of psychiatric disorders in referred adolescents with Internet addiction. Psychiatry and
Clinical Neurosciences, 67(5), 352-359. doi:10.1111/pcn. 12065

Brunborg, G. S., Mentzoni, R. A., \& Frøyland, L. R. (2014). Is video gaming, or video game addiction, associated with depression, academic achievement, heavy episodic drinking, or conduct problems? Journal of Behavioral Addictions, 3(1), 27-32. doi:10.1556/JBA.3.2014.002

Carli, V., Durkee, T., Wasserman, D., Hadlaczky, G., Despalins, R., Kramarz, E., Wasserman, C., Sarchiapone, M., Hoven, C. W., Brunner, R., \& Kaess, M. (2013). The association between pathological Internet use and comorbid psychopathology: A systematic review. Psychopathology, 46(1), 1-13. doi:10.1159/000337971

Ceyhan, A., \& Ceyhan, E. (2008). Loneliness, depression, and computer self-efficacy as predictors of problematic Internet use. CyberPsychology \& Behavior, 11(6), 699-701. doi:10. 1089/cpb.2007.0255

Chan, P. A., \& Rabinowitz, T. (2006). A cross-sectional analysis of video games and attention deficit hyperactivity disorder symptoms in adolescents. Annals of General Psychiatry, 5(1), 16. doi:10.1186/1744-859X-5-16

Derogatis, L. R. (1996). SCL-90-R: Symptom checklist-90-R: Administration, scoring, and procedures manual. Minneapolis, MN: NCS Pearson.

Derogatis, L. R. (2002). SCL-90-R: Cuestionario de 90 síntomas: Manual [SCL-90-R: Symptom checklist-90-R: Manual]. Madrid, Spain: TEA.

Du, Y., Jiang, W., \& Vance, A. (2010). Longer term effect of randomized, controlled group cognitive behavioral therapy for Internet addiction in adolescent students in Shanghai. Australian and New Zealand Journal of Psychiatry, 44(2), 129-134. doi:10.3109/00048670903282725

Engelberg, E., \& Sjöberg, L. (2004). Internet use, social skills, and adjustment. CyberPsychology \& Behavior, 7(1), 41-47. doi:10.1089/109493104322820101

Feng, W., Ramo, D. E., Chan, S. R., \& Bourgeois, J. A. (2017). Internet gaming disorder: Trends in prevalence 1998-2016. Addictive Behaviors, 75, 17-24. doi:10.1016/j.addbeh.2017. 06.010

Ferguson, C., Coulson, M., \& Barnett, J. (2011). A meta-analysis of pathological gaming prevalence and comorbidity with mental health, academic and social problems. Journal of Psychiatric Research, 45(12), 1573-1578. doi:10.1016/j. jpsychires.2011.09.005

Fernandez-Berrocal, P., Extremera, N., \& Ramos, N. (2004). Validity and reliability of the Spanish modified version of the Trait Meta-Mood Scale. Psychological Reports, 94(3), 751-755. doi:10.2466/pr0.94.3.751-755

Fuster, H., Carbonell, X., Pontes, H. M., \& Griffiths, M. D. (2016). Spanish validation of the Internet Gaming Disorder (IGD-20) Test. Computers in Human Behavior, 56, 215-224. doi:10.1016/j.chb.2015.11.050

Gentile, D., Choo, H., Liau, A., Sim, T., Li, D., Fung, D., \& Khoo, A. (2011). Pathological video game use among youths: A two-year longitudinal study. Pediatrics, 127(2), e319-e329. doi:10.1542/peds.2010-1353

Greenberg, B. S., Sherry, J. L., Lachlan, K., Lucas, K., \& Holmstrom, A. (2010). Orientations to video games among gender and age groups. Simulation \& Gaming, 41(2), 238-259. doi:10.1177/1046878108319930 
Griffiths, M. D. (2010). The role of context in online gaming excess and addiction: Some case study evidence. International Journal of Mental Health and Addiction, 8(1), 119-125. doi:10.1007/s11469-009-9229-x

Griffiths, M. D., Kuss, D. J., \& Pontes, H. M. (2016). A brief overview of Internet gaming disorder and its treatment. Australian Clinical Psychologist, 2(1), 1-12.

Griffiths, M. D., van Rooij, A. J., Kardefelt-Winther, D., Starcevic, V., Király, O., Pallesen, S., Müller, K., Dreier, M., Carras, M., Prause, N., King, D. L., Aboujaoude, E., Kuss, D. J., Pontes, H. M., Lopez Fernandez, O., Nagygyorgy, K., Achab, S., Billieux, J., Quandt, T., Carbonell, X., Ferguson, C. J., Hoff, R. A., Derevensky, J., Haagsma, M. C., Delfabbro, P., Coulson, M., Hussain, Z., \& Demetrovics, Z. (2016). Working towards an international consensus on criteria for assessing Internet gaming disorder: A critical commentary on Petry et al. (2014). Addiction, 111(1), 167-175. doi:10.1111/ add. 13057

Han, D., Kim, S. M., Lee, Y. S., \& Renshaw, P. F. (2015). The effect of family therapy on the changes in the severity of online game play and brain activity in adolescents with on-line game addiction. Psychiatry Research: Neuroimaging, 202(2), 126-131. doi:10.1016/j.pscychresns.2012.02.011

Han, D. H., Lee, Y. S., Shi, X., \& Renshaw, P. F. (2014). Proton magnetic resonance spectroscopy (MRS) in on-line game addiction. Journal of Psychiatric Research, 58, 63-68. doi:10.1016/j.jpsychires.2014.07.007

Homer, B. D., Hayward, E. O., Frye, J., \& Plass, J. L. (2012). Gender and player characteristics in video game play of preadolescents. Computers in Human Behavior, 28(5), 1782-1789. doi:10.1016/j.chb.2012.04.018

Kelleci, M., \& Inal, S. (2010). Psychiatric symptoms in adolescents with Internet use: Comparison without Internet use. Cyberpsychology, Behavior, and Social Networking, 13(2), 191-194. doi:10.1089/cyber.2009.0026

Kim, E. J., Namkoong, K., Ku, T., \& Kim, S. J. (2008). The relationship between online game addiction and aggression, self-control and narcissistic personality traits. European Psychiatry, 23(3), 212-218. doi:10.1016/j.eurpsy.2007. 10.010

Kim, K., Ryu, E., Chon, M. Y., Yeun, E. J., Choi, S. Y., Seo, J. S., \& Nam, B. W. (2006). Internet addiction in Korean adolescents and its relation to depression and suicidal ideation: A questionnaire survey. International Journal of Nursing Studies, 43(2), 185-192. doi:10.1016/j.ijnurstu. 2005.02.005

King, D. L., \& Delfabbro, P. H. (2014). Internet gaming disorder treatment: A review of definitions of diagnosis and treatment outcome. Journal of Clinical Psychology, 70(10), 942-955. doi: $10.1002 /$ jclp. 22097

King, D. L., \& Delfabbro, P. H. (2016). Features of parent-child relationships in adolescents with Internet gaming disorder. International Journal of Mental Health and Addiction, 15(6), 1270-1283. doi:10.1007/s11469-016-9699-6

King, D. L., Delfabbro, P. H., \& Griffiths, M. (2010). Cognitive behavioral therapy for problematic video game players: Conceptual considerations and practice issues. Journal of Cyber Therapy and Rehabilitation, 3(3), 261-273.

King, D. L., Delfabbro, P. H., Griffiths, M. D., \& Gradisar, M. (2012). Cognitive-behavioral approaches to outpatient treatment of Internet addiction in children and adolescents. Journal of Clinical Psychology, 68(11), 1185-1195. doi:10.1002/ jclp. 21918

King, D. L., Delfabbro, P. H., \& King, D. L. (2016). The cognitive psychopathology of Internet gaming disorder in adolescence. Journal of Abnormal Child Psychology, 44(8), 1635-1645. doi:10.1007/s10802-016-0135-y

King, D. L., Delfabbro, P. H., Wu, A. M. S., Doh, Y. Y., Kuss, D. J., Pallesen, S., Mentzoni, R., Carragher, N., \& Sakuma, H. (2017). Treatment of Internet gaming disorder: An international systematic review and CONSORT evaluation. Clinical Psychology Review, 54, 123-133. doi:10.1016/j. cpr.2017.04.002

King, D. L., Delfabbro, P. H., Zwaans, T., \& Kaptsis, D. (2013). Clinical features and axis I comorbidity of Australian adolescent pathological Internet and video game users. Australian \& New Zealand Journal of Psychiatry, 47(11), 1058-1067. doi:10.1177/0004867413491159

King, D. L., Haagsma, M. C., Delfabbro, P. H., Gradisar, M., \& Griffiths, M. D. (2013). Toward a consensus definition of pathological video-gaming: A systematic review of psychometric assessment tools. Clinical Psychology Review, 33(3), 331-342. doi:10.1016/j.cpr.2013.01.002

Király, O., Griffiths, M. D., \& Demetrovics, Z. (2015). Internet gaming disorder and the DSM-5: Conceptualization, debates, and controversies. Current Addiction Reports, 2(3), 254-262. doi:10.1007/s40429-015-0066-7

Ko, C. H., Yen, J. Y., Chen, C. C., Chen, S. H., Wu, K., \& Yen, C. F. (2006). Tridimensional personality of adolescents with Internet addiction and substance use experience. Canadian Journal of Psychiatry, 51(14), 887-894. doi:10.1177/ 070674370605101404

Ko, C.-H., Yen, J.-Y., Chen, S.-H., Wang, P.-W., Chen, C.-S., \& Yen, C.-F. (2014). Evaluation of the diagnostic criteria of Internet gaming disorder in the DSM-5 among young adults in Taiwan. Journal of Psychiatric Research, 53, 103-110. doi:10.1016/j.jpsychires.2014.02.008

Kowert, R., Festl, R., \& Quandt, T. (2014). Unpopular, overweight, and socially inept: Reconsidering the stereotype of online gamers. Cyberpsychology, Behavior and Social Networking, 17(3), 141-146. doi:10.1089/cyber.2013.0118

Kuss, D. J., \& Griffiths, M. D. (2012a). Internet gaming addiction: A systematic review of empirical research. International Journal of Mental Health and Addiction, 10(2), 278-296. doi:10.1007/s11469-011-9318-5

Kuss, D. J., \& Griffiths, M. D. (2012b). Online gaming addiction in children and adolescents: A review of empirical research. Journal of Behavioral Addictions, 1(1), 3-22. doi:10.1556/ JBA.1.2012.1.1

Kuss, D. J., Griffiths, M. D., \& Pontes, H. M. (2017). Chaos and confusion in DSM-5 diagnosis of Internet gaming disorder: Issues, concerns, and recommendations for clarity in the field. Journal of Behavioral Addictions, 6(2), 103-109. doi:10.1556/ 2006.5.2016.062

Kuss, D., van Rooij, A., Shorter, G. W., Griffiths, M. D., \& van de Mheen, D. (2013). Internet addiction in adolescents: Prevalence and risk factors. Computers in Human Behavior, 29(5), 1987-1996. doi:10.1016/j.chb.2013.04.002

Lemmens, J. S., Valkenburg, P. M., \& Peter, J. (2011). Psychosocial causes and consequences of pathological gaming. Computers in Human Behavior, 27(1), 144-152. doi:10.1016/j. chb.2010.07.015 
Lemos, S., Fidalgo, A. M., Calvo, P., \& Menéndez, P. (1992). Validación de la escala de psicopatología infanto-juvenil YSR [Validation of YSR Childhood and Youth Psychopathology Scale]. Clinica Y Salud, 3(2), 183-194.

Leung, L. (2007). Stressful life events, motives for Internet use, and social support among digital kids. CyberPsychology \& Behavior, 10(2), 204-214. doi:10.1089/cpb.2006.9967

Liebert, M. A., Lo, S., Ph, D., Wang, C., \& Fang, W. (2005). Physical interpersonal relationships and social anxiety. CyberPsychology \& Behavior, 8(1), 15-20. doi:10.1089/ cpb.2005.8.15

Lindenberg, K., Halasy, K., \& Schoenmaekers, S. (2017). A randomized efficacy trial of a cognitive-behavioral group intervention to prevent Internet use disorder onset in adolescents: The PROTECT study protocol. Contemporary Clinical Trials Communications, 6, 64-71. doi:10.1016/j.conctc.2017. 02.011

López-Fernandez, O., Honrubia-Serrano, M. L., Baguley, T., \& Griffiths, M. D. (2014). Pathological video game playing in Spanish and British adolescents: Towards the exploration of Internet gaming disorder symptomatology. Computers in Human Behavior, 41, 304-312. doi:10.1016/j.chb.2014. 10.011

Martín-Fernández, M., Matalí, J. L., García-Sánchez, S., Pardo, M., \& Castellano-Tejedor, C. (2016). Adolescentes con Trastorno por juego en Internet (IGD): Perfiles y respuesta al tratamiento [Adolescents with Internet gaming disorder (IGD): Profiles and treatment response]. Adicciones, 29(2), 125-133. doi:10.20882/adicciones. 890

Martins, A., Ramalho, N., \& Morin, E. (2010). A comprehensive meta-analysis of the relationship between emotional intelligence and health. Personality and Individual Differences, 49(6), 554-564. doi:10.1016/j.paid.2010.05.029

Masten, A. S., \& Garmezy, N. (1985). Risk, vulnerability, and protective factors in developmental psychopathology. In B. B. Lahey \& A. E. Kazdin (Eds.), Advances in clinical child psychology (Vol. 8). Boston, MA: Springer.

Mentzoni, R. A., Brunborg, G. S., Molde, H., Myrseth, H., Skouverøe, K. J. M., Hetland, J., \& Pallesen, S. (2011). Problematic video game use: Estimated prevalence and associations with mental and physical health. Cyberpsychology, Behavior, and Social Networking, 14(10), 591-596. doi:10. 1089/cyber.2010.0260

Millon, T. (1994). Millon Adolescent Clinical Inventory (MACI). Minneapolis. MN: Nacional Computers Systems.

Millon, T. (2004). MACI. Inventario Clínico para Adolescente [MACI. Clinical Inventory for adolescent]. Madrid, Spain: TEA Ediciones.

Moos, R. H., \& Moos, B. S. (1994). Family Environment Scale manual. Palo Alto, CA: Consulting Psychologists Press.

Müller, K. W., Beutel, M. E., Egloff, B., \& Wölfling, K. (2014). Investigating risk factors for Internet gaming disorder: A comparison of patients with addictive gaming, pathological gamblers and healthy controls regarding the big five personality traits. European Addiction Research, 20(3), 129-136. doi:10.1159/000355832

Müller, K. W., Janikian, M., Dreier, M., Wölfling, K., Beutel, M. E., Tzavara, C., Richardson, C., \& Tsitsika, A. (2015). Regular gaming behavior and Internet gaming disorder in European adolescents: Results from a cross-national representative survey of prevalence, predictors, and psychopathological correlates. European Child \& Adolescent Psychiatry, 24(5), 565-574. doi:10.1007/s00787-014-0611-2

Muñoz-Miralles, R., Ortega-González, R., López-Morón, M. R., Batalla-Martínez, C., Manresa, J. M., Montellà-Jordana, N., Chamarro, A., Carbonell, X., \& Torán-Monserrat, P. (2016). The problematic use of Information and Communication Technologies (ICT) in adolescents by the cross sectional JOITIC study. BMC Pediatrics, 16(140), 1-11. doi:10.1186/s12887016-0674-y

Newzoo Games. (2016). 2016 Global Games Market Report. Retrieved January 19, 2018, from https://newzoo.com/ insights/articles/global-games-market-reaches-99-6-billion-2016mobile-generating-37/

Ng, B., \& Wiemer-Hastings, P. (2005). Addiction to the Internet and online gaming. CyberPsychology \& Behavior, 8(2), 110-113. doi:10.1089/cpb.2005.8.110

Parker, J. D., Summerfeldt, L. J., Taylor, R. N., Kloosterman, P. H., \& Keefer, K. V. (2013). Problem gambling, gaming and Internet use in adolescents: Relationships with emotional intelligence in clinical and special needs samples. Personality and Individual Differences, 55(3), 288-293. doi:10.1016/j. paid.2013.02.025

Parker, J. D., Taylor, R. N., Eastabrook, J. M., Schell, S. L., \& Wood, L. M. (2008). Problem gambling in adolescence: Relationships with Internet misuse, gaming abuse and emotional intelligence. Personality and Individual Differences, 45(2), 174-180. doi:10.1016/j.paid.2008.03.018

Petry, N. M., Rehbein, F., Gentile, D. A., Lemmens, J. S., Rumpf, H. J., Mößle, T., Bischof, G., Tao, R., Fung, D. S., Borges, G., Auriacombe, M., González Ibáñez, A., Tam, P., \& O’Brien, C. P. (2014). An international consensus for assessing Internet gaming disorder using the new DSM-5 approach. Addiction, 109(9), 1399-1406. doi:10.1111/add.12457

Pontes, H. M., \& Griffiths, M. D. (2014). Assessment of Internet gaming disorder in clinical research: Past and present perspectives. Clinical Research and Regulatory Affairs, 31(2-4), 35-48. doi:10.3109/10601333.2014.962748

Pontes, H. M., Király, O., Demetrovics, Z., \& Griffiths, M. D. (2014). The conceptualisation and measurement of DSM-5 Internet gaming disorder: The development of the IGD-20 Test. PLoS One, 9(10), e110137. doi:10.1371/journal.pone. 0110137

Rehbein, F., Psych, G., Kleimann, M., Mediasci, G., \& Mößle, T. (2010). Prevalence and risk factors of video game dependency in adolescence: Results of a German nationwide survey. Cyberpsychology, Behavior, and Social Networking, 13(3), 269-277. doi:10.1089/cyber.2009.0227

Salovey, P., Mayer, J., Goldman, S. L., Turvey, C., \& Palfai, T. P. (1995). Emotional attention, clarity and repair exploring emotional intelligence using the Trait Meta-Mood Scale. In J. W. Pennebaker (Ed.), Emotion, disclosure, and health (pp. 125154). Washington, DC: American Psychiatric Association.

Schneider, L. A., King, D. L., \& Delfabbro, P. H. (2017). Maladaptive coping styles in adolescents with Internet gaming disorder symptoms. International Journal of Mental Health and Addiction, 16(4), 905-916. doi:10.1007/s11469-0179756-9

Schwartz, R. H. (2013). Excessive participation in online Internet action games by two American teenagers: Case report, description of extent of overuse, and adverse consequences. Pediatrics, 3, 201-203. doi:10.4236/ojped.2013.33035 
Seisdedos, N., Victoria de la Cruz, M., \& Cordero, A. (1989). Escalas de Clima Social (FES) [Social Climate Scales]. Madrid, Spain: TEA Ediciones.

Shapira, N. A., Goldsmith, T. D., Keck, P. E., Jr., Khosla, U. M., \& McElroy, S. L. (2000). Psychiatric features of individuals with problematic Internet use. Journal of Affective Disorders, 57(1-3), 267-272. doi:10.1016/S0165-0327(99)00107-X

Smyth, J. M. (2007). Beyond self-Selection in video game play: An experimental examination of the consequences of massively Multiplayer Online Role-Playing Game play. CyberPsychology \& Behavior, 10(5), 717-721. doi:10.1089/cpb.2007.9963

Steinhausen, H. C., \& Metzke, C. W. (2001). Risk, compensatory, vulnerability, and protective factors influencing mental health in adolescence. Journal of Youth and Adolescence, 30(3), 259-280. doi:10.1023/A:1010471210790

Tejeiro, R. A., Gómez-Vallecillo, J. L., Pelegrina, M., Wallace, A., \& Emberley, E. (2012). Risk factors associated with the abuse of video games in adolescents. Scientific Research, 3(4), 310-314. doi:10.4236/psych.2012.34044

Torres-Rodríguez, A., \& Carbonell, X. (2015). Adicción a los videojuegos en línea: Tratamiento mediante el programa PIPATIC [Online videogame addiction: Treatment with PIPA-TIC program]. Aloma, 33(2), 67-75.

Torres-Rodríguez, A., Griffiths, M. D., \& Carbonell, X. (2018). The treatment of Internet gaming disorder: A brief overview of the PIPATIC program. International Journal of Mental Health and Addiction, 16(4), 1000-1015. doi:10.1007/s11469-0179825-0

Torres-Rodríguez, A., Griffiths, M. D., Carbonell, X., FarriolsHernando, N., \& Torres-Jiménez, E. (2017). Internet gaming disorder treatment: A case study evaluation of four adolescent problematic gamers. International Journal of Mental Health and Addiction. Advance online publication. doi:10.1007/ s11469-017-9845-9

van Rooij, A. J., Kuss, D. J., Griffiths, M. D., Shorter, G. W., Schoenmakers, M. T., \& Van De Mheen, D. (2014). The (co-) occurrence of problematic video gaming, substance use, and psychosocial problems in adolescents. Journal of Behavioral Addictions, 3(3), 157-165. doi:10.1556/JBA.3.2014.013

Voss, A., Cash, H., Hurdiss, S., Bishop, F., Klam, W. P., \& Doan, A. P. (2015). Case report: Internet gaming disorder associated with pornography use. Yale Journal of Biology and Medicine, 88(3), 319-324.
Wan, C., \& Chiou, W. (2006). Why are adolescents addicted to online gaming? An interview study in Taiwan. CyberPsychology \& Behavior, 9(6), 762-766. doi:10.1089/cpb.2006.9.762

Williams, D., Yee, N., \& Caplan, S. E. (2008). Who plays, how much, and why? Debunking the stereotypical gamer profile. Journal of Computer-Mediated Communication, 13(4), 993-1018. doi:10.1111/j.1083-6101.2008.00428.x

Wölfling, K., Beutel, M. E., Dreier, M., \& Müller, K. W. (2014). Treatment outcomes in patients with Internet addiction: A clinical pilot study on the effects of a cognitive-behavioral therapy program. BioMed Research International, 2014(10), 425924. doi:10.1155/2014/425924

Wood, R., Gupta, R., Derevensky, J., \& Griffiths, M. (2004). Video game playing and gambling in adolescents: Common risk factors. Journal of Child \& Adolescent Substance Abuse, 14(1), 77-100. doi:10.1300/J029v14n01_05

World Health Organization [WHO]. (2014). Public health implications of excessive use of the Internet, computers, smartphones and similar electronic devices: Meeting report. Geneva, Switzerland: World Health Organization.

WHO. (2016). Gaming disorder. Retrieved November 19, 2017, from http://id.who.int/ icd/entity/1448597234

Yan, W., Li, Y., \& Sui, N. (2014). The relationship between recent stressful life events, personality traits, perceived family functioning and Internet addiction among college students. Stress and Health, 30(1), 3-11. doi:10.1002/smi.2490

Yao, Y. W., Chen, P. R., Li, C. S. R., Hare, T. A., Li, S., Zhang, J. T., Liu, L., Ma, S.-S., \& Fang, X. Y. (2017). Combined reality therapy and mindfulness meditation decrease intertemporal decisional impulsivity in young adults with Internet gaming disorder. Computers in Human Behavior, 68, 210-216. doi:10.1016/j.chb.2016.11.038

Young, K. (2009). Understanding online gaming addiction treatment issues for adolescents. American Journal of Family Therapy, 37(5), 355-372. doi:10.1080/01926180902942191

Young, K. S. (2013). Treatment outcomes using CBT-IA with Internet-addicted patients. Journal of Behavioral Addictions, 2(4), 209-215. doi:10.1556/JBA.2.2013.4.3

Zadra, S., Bischof, G., Besser, B., Bischof, A., Meyer, C., John, U., \& Rumpf, H. J. (2016). The association between Internet addiction and personality disorders in a general populationbased sample. Journal of Behavioral Addictions, 5(4), 691-699. doi:10.1556/2006.5.2016.086 